\title{
Dielectric properties of vanadium doped barium titanate synthesized via high-energy ball milling*
}

\author{
Piotr Dulian $^{1 \dagger}$, Wojciech Bą ${ }^{2}$, Krystyna WieczoreK-CiUrowa $^{1}$, CZeSŁaw Kajtoch ${ }^{2}$ \\ ${ }^{1}$ Faculty of Chemical Engineering and Technology, Cracow University of Technology, \\ 24, Warszawska Str., 31-155 Cracow, Poland \\ ${ }^{2}$ Institute of Physics, Pedagogical University, 2, Podchorążych Str., 30-084 Cracow, Poland
}

\begin{abstract}
The study shows the advisability of using a mechanochemical synthesis method, based on a high-energy planetary ball milling, to a modification of barium titanate by a vanadium doping. This method improves useful properties of $\mathrm{BaTi}_{0.95} \mathrm{~V}_{0.05} \mathrm{O}_{3}$ as a capacitor material. It has a high value of electric permittivity $\varepsilon^{\prime}$ in the wide range of temperature and low dielectric losses $\varepsilon^{\prime \prime}$ as well as a low electrical conductivity.
\end{abstract}

Keywords: mechanochemistry; high-energy ball milling; perovskites; ferroelectric ceramics; barium titanate

(C) Wroclaw University of Technology.

\section{Introduction}

Among the materials of perovskite structure $\left(\mathrm{ABO}_{3}\right)$ the oxides with ferroelectric properties play an important role, because of their technical and technological importance $[1,2]$. One of the well-known oxides of this type is barium titanate, which due to a high value of electric permittivity at room temperature $(\varepsilon \approx 1500)$ is an interesting material for the production of capacitors [3, 4]. It is necessary to search for ceramic electrotechnical materials with better and better functional properties to meet the requirements of the continuously progressing miniaturization of electronic devices. The study on barium titanate currently conducted is focused on increasing the value of its electric permittivity $\left(\varepsilon^{\prime}\right)$ at room temperature and at the same time maintaining the lowest possible dielectric losses. Such properties of $\mathrm{BaTiO}_{3}$ can be achieved through a modification of its crystal structure by a substitution of foreign metal

\footnotetext{
${ }^{*}$ This paper was presented at XIX International Seminar on Physics and Chemistry of Solids (ISPCS) and Advanced Materials, Częstochowa, 12 - 15 June, 2013.

${ }^{\dagger}$ E-mail: piotrdulian@indy.chemia.pk.edu.pl
}

ions to produce a material with an appropriate $\mathrm{Ba} / \mathrm{Ti}$ ratio and size of grains [5-8]. Despite the physicochemical investigations of this compound conducted for decades there is still no clear explanation for the origins of its ferroelectricity. Depending on the chemical composition and the number of crystal structure defects, $\mathrm{BaTiO}_{3}$ is characterized by the diversity of ferroelectric behaviors, including the significantly different temperatures of ferroelectric-paraelectric type phase transitions and various values of spontaneous polarization. There is a large number of works, both theoretical and experimental, concerning an improvement of functional properties of $\mathrm{BaTiO}_{3}$. Different types of crystal lattice modification, e.g. $\mathrm{A}\left(\mathrm{B}^{\prime} \mathrm{B}^{\prime \prime}\right) \mathrm{O}_{3},\left(\mathrm{~A}^{\prime} \mathrm{A}^{\prime \prime}\right) \mathrm{BO}_{3}$ and $\left(\mathrm{A}^{\prime} \mathrm{A}^{\prime \prime}\right)\left(\mathrm{B}^{\prime} \mathrm{B}^{\prime \prime}\right) \mathrm{O}_{3}$ are known [9-12]. The effects of the substitution of a number of cations having different valence, for example $\mathrm{Hf}^{4+} \mathrm{Mn}^{4+}, \mathrm{Tb}^{3+} \mathrm{Fe}^{3+} \mathrm{Er}^{3+} \mathrm{Sb}^{3+} \mathrm{La}^{3+}$, in the appropriate sublattices of barium titanate are extensively investigated [13-19]. However, there is little information about the influence of vanadium ions presence in the barium titanate lattice on its microstructure and ferroelectric properties. Moura et al. [20] showed that an addition of vanadium diffused the maximum of electric permittivity and decreased its value in the region of the ferroelectric 
transition of $\mathrm{BaZr}_{0.1} \mathrm{Ti}_{0.9} \mathrm{O}_{3}$. The influence of the vanadium addition on the dielectric properties of strontium titanate and strontium bismuth niobate was investigated by Liu et al. [21], Bandyopadhyay et al. [22] and Wu et al. [23]. According to Nogucki et al. [24] and Zeng et al. [25] the substitution of

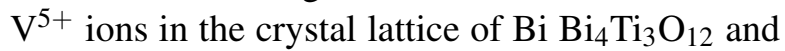
$\mathrm{CaBi}_{4} \mathrm{Ti}_{4} \mathrm{O}_{15}$ may cause an increase in a residual polarization of these ceramics.

According to Cai et al. [26] the addition of vanadium accelerates grain growth of $\mathrm{BaTiO}_{3}$ ceramics and it results in an abnormal grain growth of barium titanate ceramics with higher vanadium concentration. Vanadium doping can increase the Curie temperature and decrease the dielectric loss of $\mathrm{BaTiO}_{3}$ ceramics.

Based on the researches [27-30] it was found that besides of the presence of the modifier in the form of vanadium ions, the appropriate size of grains $(\approx 1 \mu \mathrm{m})$ and the uniform distribution of the grain size are extremely important to obtain $\mathrm{BaTiO}_{3}$ ceramics characterized by the high dielectric permittivity at room temperature $(\varepsilon \approx$ $3500)$. Hence, the choice of a method for producing ceramics, which determines the morphology and the microstructure of grains is very important.

Polycrystalline barium titanate is now manufactured on an industrial scale by a high-temperature synthesis in solid phase involving the long-lasting heating of the mixture containing appropriate substrates at a temperature of about $1623 \mathrm{~K}$ [31]. However, this method does not allow one to produce a fine-crystalline material. In addition, the products contain sinters, which negatively influences on the dielectric properties of the electroceramics. The other methods of preparing $\mathrm{BaTiO}_{3}$ such as hydrothermal [32], co-precipitation [33], a spray pyrolysis [34] or sol-gel [35] are devoid of these limitations. However, in view of the complexity of the processes and apparatus as well as the need to use metalorganic substrates, these methods have not found a widespread use on an industrial scale. The great alternative for these methods is the mechanochemical synthesis combining simplicity and the ability to produce materials with a submicrosize and even nanosize of grains [36-38]. Barium titanate obtained by this method, because of the grain size, the lack of sinters and thanks to the properly selected material of grinding balls has much better functional properties compared with $\mathrm{BaTiO}_{3}$ obtained by other methods.

In this paper the possibility of using the mechanochemical synthesis method based on high-energy ball milling to modify barium titanate by the substitution of $\mathrm{V}^{5+}$ ions in the place of $\mathrm{Ti}^{5+}$ ions was examined. The results of the microstructure and dielectric measurements in terms of the ferroelectric properties of $\mathrm{BaTi}_{0.95} \mathrm{~V}_{0.05} \mathrm{O}_{3}$ were presented.

\section{Experimental}

\subsection{Synthesis materials}

All materials used were oxides: $\mathrm{BaO}$ (Sigma Aldrich, $90 \%$ ), $\mathrm{TiO}_{2}$ (Evonik Degussa P25 GmbH, $98.0 \%$ ) and $\mathrm{V}_{2} \mathrm{O}_{5}(\mathrm{POCH}, 99.5 \%)$. As the reaction vessels and balls were made of steel or $\mathrm{ZrO}_{2}$, metallic iron or zirconia were present in final products [38].

\subsection{Synthesis equipment and procedures}

A stoichiometric molar ratio of oxides to $\mathrm{BaTi}_{1-x} \mathrm{~V}_{x} \mathrm{O}_{3} 0.00 \leqslant \mathrm{x} \leqslant 0.10$ was mixed by hand in an agate mortar in order to obtain a homogenous mixture. This mixture was then subjected to the mechanochemical treatment using a high-energy planetary ball-mill Pulverisette 6 (Fritsch $\mathrm{GmbH}$, Germany). The milling was conducted in air with the vessel and balls $(\varnothing=10 \mathrm{~mm})$ made of $\mathrm{Cr}-\mathrm{Ni}$ steel (sample BTV5/Fe), and $\mathrm{ZrO}_{2}$ (sample BTV5/Zr). The vessel was rotated at $550 \mathrm{rpm}$ for 3 hours, with a ball-to-powder weight ratio (BPR) of $30: 1$.

Barium titanate (sample BT) was synthesized with the use of a high-temperature method as a reference sample [31]. A stoichiometric mixture of oxides was formed into a tablet and heated for 4 hours at $1623 \mathrm{~K}$ in a Nabertherm HTC 03/15 laboratory furnace. This procedure was repeated three times. 


\subsection{Characterization of as-synthesized materials}

The as-synthesized materials were analyzed via a powder $\mathrm{X}$-ray diffraction with a $\mathrm{CuK} \alpha$ source on an X'Pert Philips instrument, for $2 \theta=10-90^{\circ}$ with a step size of $0.01^{\circ}$. The identification of the material was made according to a JCPDS table.

The SEM images of the microstructure, morphology and elemental composition of the obtained ceramics were taken with a HITACHI S-4700 instrument with X-ray EDS analysis.

For the purposes of testing the electrical properties, a small sample was taken and pressed into a disc-pellet with a diameter of $7 \mathrm{~mm}$ and $2.5 \mathrm{~mm}$ thickness, which was then heated in a Nabertherm HTC 03/15 laboratory furnace for 1 hour at $1373 \mathrm{~K}$ and painted with silver electrodes. Dielectric spectroscopy measurements were conducted at a frequency between $20 \mathrm{~Hz}$ and $1 \mathrm{MHz}$, with the use of an LCR Agilent 4284A instrument with QUATRO KRIO 4.0 temperature and WINData 5.62 software (Novocontrol). All trials were carried out under nitrogen atmosphere. The measurements were performed at temperature between $173 \mathrm{~K}$ and $473 \mathrm{~K}$, in $5 \mathrm{~K}$ increments. The amplitude of measuring voltage was $1 \mathrm{~V}$.

\section{Results and discussion}

\subsection{Phase analysis and morphology of} $\operatorname{BaTi}_{1-x} \mathbf{V}_{x} \mathbf{O}_{3} \mathbf{x}=\mathbf{0 . 0 5}$ powders obtained via mechanochemical and high-temperature methods

The modifications of barium titanate by the vanadium ions were carried out according to the reaction:

$$
\begin{aligned}
& \mathrm{BaO}+1-x \mathrm{TiO}_{2}+x \mathrm{~V}_{2} \mathrm{O}_{5} \rightarrow \\
& \rightarrow \mathrm{BaTi}_{1-x} \mathrm{~V}_{x} \mathrm{O}_{3}(0.00 \leqslant x \leqslant 0.10)
\end{aligned}
$$

Depending on the method used in the synthesis, various limits of $\mathrm{V}_{2} \mathrm{O}_{5}$ solubility in $\mathrm{BaTiO}_{3}$ have been observed. In the case of the mechanochemical method, the $\mathrm{BaTi}_{1-x} \mathrm{~V}_{x} \mathrm{O}_{3}$ solid solutions are formed to the maximum value of $\mathrm{x}=0.05$. This is evidenced by the $\mathrm{BaTiO}_{3}$ monophasic systems in the XRD diffraction patterns (Fig. 1). Above this amount of modifier a second phase of $\mathrm{Ba}_{3}\left(\mathrm{VO}_{4}\right)_{2}$ is observed. The product was obtained only by the high-energy milling (BTV5/Fe, BTV5/Zr) regardless of the material of milling balls i.e. steel or $\mathrm{ZrO}_{2}$. Modified barium titanate, obtained in this way, was characterized by the smaller size of grains evidenced by the low intensity of diffraction reflexes and their large widths compared with pure $\mathrm{BaTiO}_{3}$ prepared by the high-temperature synthesis in solid phase (BT) method.

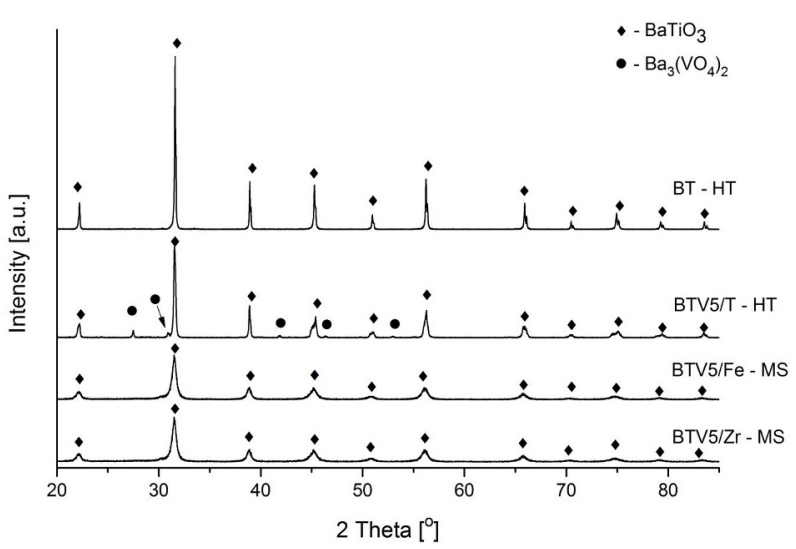

Fig. 1. Comparison of $\mathrm{X}$-ray powder patterns of $\mathrm{BaO}-\mathrm{TiO}_{2}-\mathrm{V}_{2} \mathrm{O}_{5}$ mixture after hightemperature (HT) and mechanochemical syntheses (SM) (Pulverisette- 6 mill, $\mathrm{rpm}=550$, $\mathrm{BPR}=30: 1)$.

The formation of the solid solution with $5 \%$ of vanadium ions doping in barium titanate, using the high-temperature synthesis in solid phase did not succeed. This is shown by the additional diffraction reflexes corresponding to $\mathrm{Ba}_{3}\left(\mathrm{VO}_{4}\right)_{2}$ next to $\mathrm{BaTiO}_{3}$ phase (sample BTV5/T).

Similar to the observations made by Cai et al. [23], a significant influence of vanadium oxide presence on the microstructure of $\mathrm{BaTiO}_{3}$ ceramics has been observed. The presented SEM micrographs (Fig. 2) show the uneven distribution of grain size and an increase in porosity of the material with $5 \%$ addition of $\mathrm{V}_{2} \mathrm{O}_{5}$ in all samples, regardless of the used synthesis method. Such differences in the microstructure compared with pure barium titanate, are caused by changes in the 
degree of oxidation and the formation of the lower oxides of vanadium, i.e. $\mathrm{V}_{2} \mathrm{O}_{3}, \mathrm{VO}_{2}$, VO. During such a transition, oxygen abstraction progressively takes place, which forms a visible porous structure. The ceramics obtained by the mechanochemical method has much smaller grain size in comparison with $\mathrm{BaTiO}_{3}$ produced by the high-temperature method.
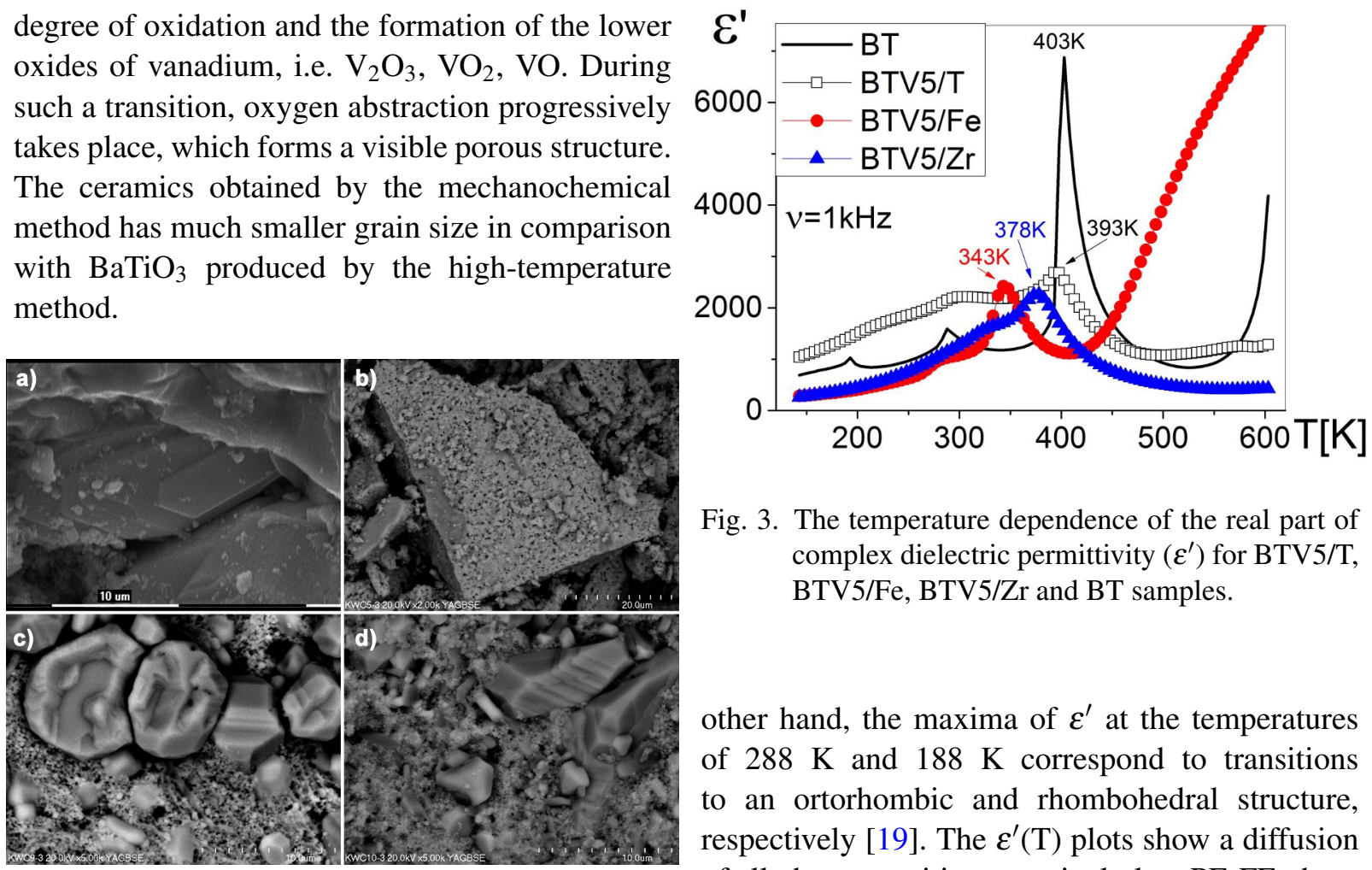

Fig. 3. The temperature dependence of the real part of complex dielectric permittivity $\left(\varepsilon^{\prime}\right)$ for BTV5/T, BTV5/Fe, BTV5/Zr and BT samples.

Fig. 2. SEM micrographs of ceramics samples obtained by the high-temperature method: (a) pure $\mathrm{BaTiO}_{3}$ (BT), (b) $\mathrm{BaTiO}_{3}$ with $\mathrm{V}_{2} \mathrm{O}_{5} 5$ wt.\% (BTV5/T) and the samples obtained by mechanochemical method: (c) (BTV5/Zr), (d) (BTV5/Fe).

\subsection{Electrical properties of modified barium titanate}

The dielectric properties of the BTV5/T, BTV5/Fe, BTV5/Zr and BT ferroelectric ceramics are described by the temperature dependences of the real $\left(\varepsilon^{\prime}\right)$ and imaginary $\left(\varepsilon^{\prime \prime}\right)$ parts of electric permittivity.

The plots of $\varepsilon^{\prime}(\mathrm{T})$ for investigated samples are presented for the frequency of electric field of $1 \mathrm{kHz}$ in Fig. 3. The temperatures corresponding to any maxima of $\varepsilon^{\prime}$ have not changed in the whole measured frequency range. For ferroelectric ceramic BT these maxima correspond to their structural phase transitions. At the temperature of $403 \mathrm{~K}$ a classic paraelectric-ferroelectric (PE-FE) phase transition with a simultaneous change from a cubic to tetragonal structure occurs. On the

other hand, the maxima of $\varepsilon^{\prime}$ at the temperatures of $288 \mathrm{~K}$ and $188 \mathrm{~K}$ correspond to transitions to an ortorhombic and rhombohedral structure, respectively [19]. The $\varepsilon^{\prime}(\mathrm{T})$ plots show a diffusion of all phase transitions, particularly a PE-FE phase transition, for the samples of solid solution BTV5, regardless of the synthesis method. The values of the maxima of $\varepsilon^{\prime}$ are about three times smaller than the value of the maximum at the temperature of $403 \mathrm{~K}$ for BT ceramics. The phase transitions for BTV5/T, BTV5/Fe and BTV5/Zr samples occur at temperatures of $393 \mathrm{~K}, 343 \mathrm{~K}$ and $378 \mathrm{~K}$, respectively.

Below the phase transition PE-FE none of these samples exhibits a distinct maximum indicating a low-temperature structural transformations as in the case of BT ceramics. It can be postulated, that the diffuse nature of the phase transitions in BTV5 ceramics is caused by the substitution of ions of different valence in a cation sublattice. In the range of temperatures above PE-FE transition (paraelectric phase) the plots of $\varepsilon^{\prime}(\mathrm{T})(v=1 \mathrm{kHz})$ indicate the increasing participation of electrical conductivity.

The character of these changes for investigated samples has been presented in Fig. 4 as a $\varepsilon^{\prime \prime}(\mathrm{T})$ function. The dielectric losses in the paraelectric phase represented by $\varepsilon^{\prime \prime}$ increase rapidly. This behavior of $\varepsilon^{\prime \prime}(\mathrm{T})$ dependence evidences the 


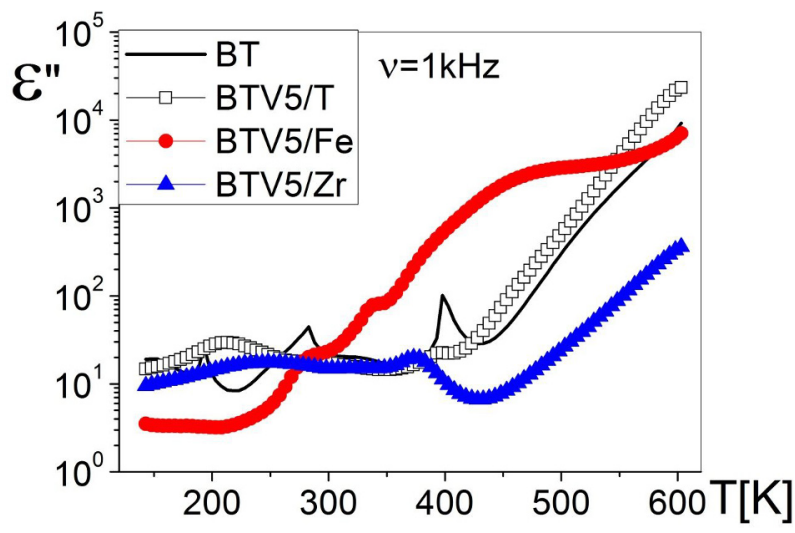

Fig. 4. The temperature dependence of the imaginary part of complex dielectric permittivity $\left(\varepsilon^{\prime \prime}\right)$ for BTV5/T, BTV5/Fe, BTV5/Zr and BT samples.

dominant participation of d.c. component of electrical conductivity in dielectric losses.

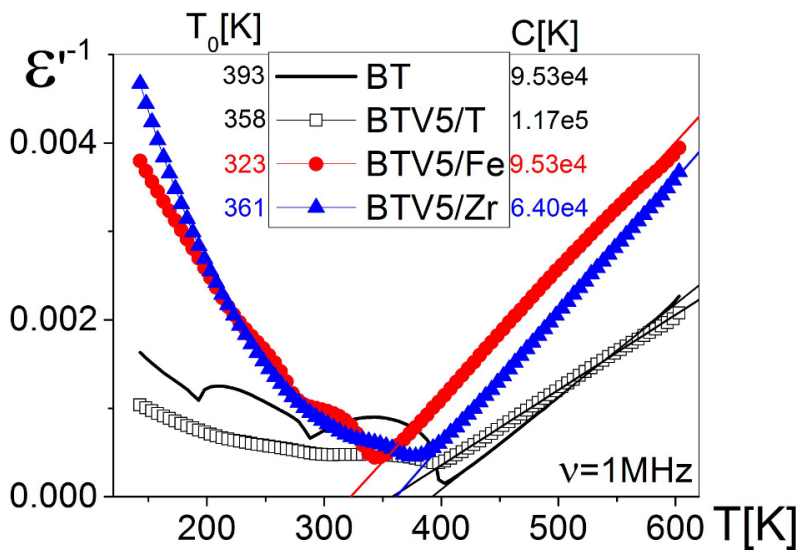

Fig. 5. The inverse of the real part of complex dielectric permittivity $\left(1 / \varepsilon^{\prime}\right)$ as a function of temperature for BTV5/T, BTV5/Fe, BTV5/Zr and BT samples.

The temperature dependences of the inverse of the real part of electric permittivity $1 / \varepsilon^{\prime}(\mathrm{T})$ for the studied samples in the paraelectric phase are presented in Fig. 5. The plots of $1 / \varepsilon^{\prime}(\mathrm{T})$ for BT ( $\mathrm{T}>403 \mathrm{~K}), \mathrm{BTV} 5 / \mathrm{T}(\mathrm{T}>393 \mathrm{~K})$, BTV5/Fe $(\mathrm{T}>343 \mathrm{~K})$ and BTV5/Zr $(\mathrm{T}>378 \mathrm{~K})$ confirm the compliance of Curie-Weiss law, which is given by the following equation:

$$
\varepsilon=\frac{C}{T-T_{0}}
$$

where: $C$ is the Curie-Weiss constant, $T_{0}-$ is the Curie-Weiss temperature.

The constants $\mathrm{C}$ and $\mathrm{T}_{0}$ determined based on a linear regression procedure at frequency of $1 \mathrm{kHz}$ for the BT sample are $9.53 \times 10^{4} \mathrm{~K}$ and $393 \mathrm{~K}$, respectively (Fig. 5). The values obtained from a linear fitting for BTV5/T are $1.17 \times 10^{5} \mathrm{~K}$ and $358 \mathrm{~K}$, respectively while for BTV $5 / \mathrm{Fe}$ and BTV5/Zr these constants are $6.92 \times 10^{4} \mathrm{~K}$ and $323 \mathrm{~K}$, and $6.40 \times 10^{4} \mathrm{~K}$ and $361 \mathrm{~K}$, respectively. The geometrical illustration of equation (2) does not reveal all the features of phase transition, namely a degree and range of its diffusion. Therefore the following relation describing the temperature dependence of permittivity was proposed [18]:

$$
\varepsilon^{-1}=\varepsilon_{m}^{-1}+A\left(T-T_{m}\right)^{\gamma}
$$

where: $\varepsilon_{m}$ is the maximum value of dielectric permittivity, $T_{m}$ - temperature corresponding to $\varepsilon_{m}$, $A$ and $\gamma$ are constants for a chosen frequency.

In the classical phase transition the value of $\gamma$ is close to 1 , while in diffuse transition it is close to 2. For investigated ceramics the value of $\gamma$ close to 2 for BT sample indicates the classical phase transition (first order) PE-FE. In the case of BTV5/T, BTV5/Fe and BTV5/Zr samples two ranges of linear dependences can be distinguished (Fig. 6).

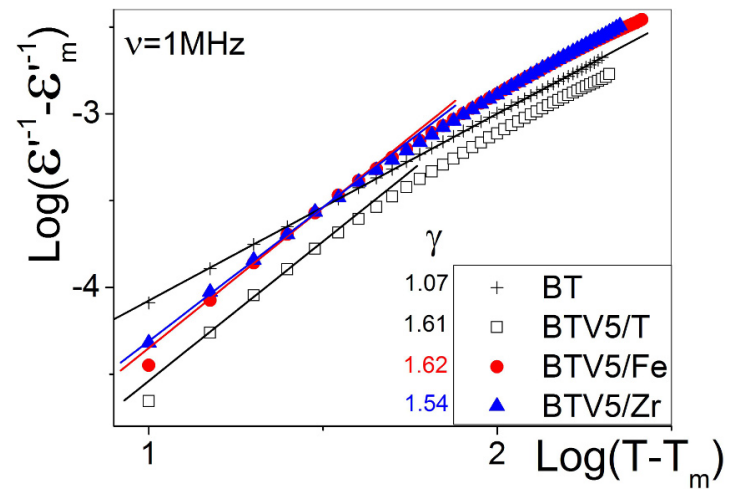

Fig. 6. The dependence of $\log \left(\varepsilon^{\prime-1}-\varepsilon_{m}^{\prime-1}\right)$ on $\log \left(\mathrm{T}-\mathrm{T}_{m}\right)$ for BTV5/T, BTV5/Fe, BTV5/Zr and BT samples.

The fitting at the temperature ranging up to $40 \mathrm{~K}$ above the PE-FE phase transition confirms the 
diffusion of these phase transitions $(\gamma \approx 1.6)$. The values of $\gamma$ obtained at temperatures above $100 \mathrm{~K}$ of PE-FE phase transition reveal a slight diffusion of the phase transition, which is characteristic of the BT sample. The dielectric losses of investigated samples were also presented by the dependence of a.c. conductivity on the inverse of temperature in so called Arrhenius system (Fig. 7).

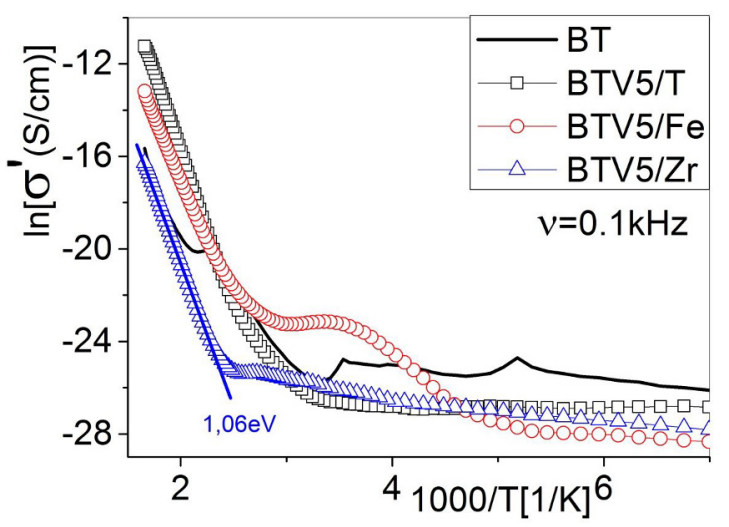

Fig. 7. A plot of the a.c. conductivity $\left(\sigma^{\prime}\right)$ in the Arrhenius system with frequency measurement field of $100 \mathrm{~Hz}$ for BTV5/T, BTV5/Fe, BTV5/Zr and BT samples.

The character of the a.c. conductivity plots indicates a complex mechanism of electric charge transport. For the BT sample the changes in the $\ln \left(\sigma^{\prime}\right)=\mathrm{f}(1000 / \mathrm{T})$ plot correspond to the $\varepsilon^{\prime}(\mathrm{T})$ dependence which characterizes phase transitions. In the range of high temperatures (paraelectric phase) the linear straight sections are observed which indicates the activation nature of a.c. conductivity. The thermal activation energies, determined by a linear regression method, at the frequency of measured field $v=0.1 \mathrm{~Hz}$, are about $1.0 \mathrm{eV}$. Since the change in the slops of straight sections is small, it can be assumed that in the investigated samples the transport of electric charge proceeds according to the same mechanism. The obtained values of activation energy are typical of semiconductors.

The replacement of $\mathrm{Ti}^{+4}$ by $\mathrm{V}^{+5}$ ions in $\mathrm{BaTiO}_{3}$ ceramics decreases both the temperature of the PE-FE phase transition and the value of electric permittivity $\left(\varepsilon^{\prime}\right)$ corresponding to this phase transition. Simultaneously the diffusion of PE-FE phase transition appears. The additional presence of zirconium and iron ions in the investigated samples, resulting from the way in which they were obtained, has a significant effect on the dielectric properties. The temperature dependence of the dielectric loss shows a dominant influence on the transport of free charge carriers, and the diffuseness of phase transitions.

\section{Conclusions}

The comparison of both the mechanochemical and high-temperature methods used to prepare barium titanate doped with vanadium indicates the possibility to forming the solid solution of $\mathrm{BaTi}_{1-x} \mathrm{~V}_{x} \mathrm{O}_{3}$ type with a higher degree of modifier substitution $(x \leqslant 0.05)$ with the use of the high-energy ball milling technique. For example, the addition of $5 \% \mathrm{~V}_{2} \mathrm{O}_{5}$ to $\mathrm{BaTiO}_{3}$ during the high-temperature synthesis leads to a biphasic system (solid solution and $\left.\mathrm{Ba}_{3}\left(\mathrm{VO}_{4}\right)_{2}\right)$. However, this does not cause significant differences in the ferroelectric properties of the obtained products.

The doping of barium titanate by vanadium causes an improvement of its functional properties as a capacitor material. It reveals the high value of electric permittivity $\left(\varepsilon^{\prime}\right)$ in the wide temperature range (a visible diffusion of phase transitions). $\mathrm{BaTi}_{0.95} \mathrm{~V}_{0.05} \mathrm{O}_{3}$ obtained by the mechanochemical method particularly with $\mathrm{ZrO}_{2}$ additions is characterized by the best dielectric properties (low dielectric losses $\left(\varepsilon^{\prime \prime}\right)$, high value of $\left(\varepsilon^{\prime}\right)$, low electrical conductivity).

It can be stated that high-energy ball milling has the advantage of being a simple, easily-scalable, green method for electroceramics production that requires less energy than high-temperature synthesis technique.

\section{Acknowledgements}

This study was supported by the National Science Centre Poland, Project DEC-2012/05/N/ST8/03764.

\section{References}

[1] BARRANCo A.P. (Ed.), Advances in ferroelectrics, InTech, Rijeka, 2013.

[2] Heartling G.H., J. Am. Ceram. Soc., 82 (1999), 797. 
[3] Arlt G., Hennings D., De With G., J. Appl. Phys., 58 (1985), 1619.

[4] TAng H., Lin Y., Sodano H.A., Adv. Energy Mater., 3 (2013), 451.

[5] Choi Y.K., Koshina T., Takeda H., Teranishi T., Tsurumi T., Appl. Phys. Lett., 97 (2010), 212907.

[6] LeE J.K., Hong K.S., Jang J.W., J. Am. Ceram. Soc., 84 (2001), 2001.

[7] Lin T.F., Hu C.T., J. Am. Ceram. Soc., 73 (1990), 531.

[8] Pinceloup P., Courtois C., Leriche A., Thierry B., J. Am. Ceram. Soc., 82 (1999), 3049.

[9] LiU R., Xuan Y., JiA Y.Q., Mater. Chem. Phys., 57 (1998), 81.

[10] Borstel G., Eglitis R.I., Kotomin E.A., Heifets E., J. Cryst. Growth, 237 (2002), 687.

[11] Hirose N., SKaKle J.M.S., West A.R., J. Electroceram., 3 (1999), 233.

[12] Kajtoch C., BĄK W., Garbarz-Glos B., Condens. Matter Phys., 16 (2013), 31702.

[13] Garbarz-Glos B., Piekarczyk W., Smeltere I., Smiga W., Antonova M., Ferroelectrics, 436 (2012), 87.

[14] Anwar S., Sagdeo P.R., Lalla N.P., Mater. Res. Bull., 43 (2008), 1761.

[15] Yang H., Zhou C., LiU X., Zhou Q., Chen G., LI W., Wang H., J. Eur. Ceram. Soc., 33 (2013), 1177.

[16] Buscaglia M.T., Buscaglia V., Viviani M., Nanni P., Hanuskova M., J. Eur. Ceram. Soc., 20 (2000), 1997.

[17] Jung Y.S., NA E.S., PAIK U., LeE J., Kim J., Mater. Res. Bull., 37 (2002), 1633.

[18] Garbarz-Glos B., BąK W., MolaK A., Kalvane A., Phase Transit., (2012).

[19] BąK W., Kajtoch C., StarzyK F., Mater. Sci. Eng. $B$-Adv., 100 (2003), 9.

[20] Moura F., Simões A.Z., Cavalcante L.S., Zaghete M.A., Varela J.A., Longo E., J. Alloy. Compd., 466 (2008), 115.

[21] LiU S.J., Zenou V.Y., Sus I., Kotani T., SChilfgaArde M.V., NeWMan N., Acta Mater., 55 (2007), 2647.
[22] Bandyopadhyay S., LiU S.J., Tang Z.Z., Singh R.K., NeWMAN N., Acta Mater., 57 (2009), 4935.

[23] Wu Y., Nguyen C., Seraji S., Forbess M.J., Limmer S.J., Chou T., CaO G.Z., J. Am. Ceram. Soc., 84 (2001), 2882.

[24] Noguchi Y., Miyayama M., Appl. Phys. Lett., 78 (2001), 1903.

[25] Zeng J.T., Li Y.X., YAng Q.B., Yin Q.R., Mater. Sci. Eng. B-Adv., 117 (2005), 241.

[26] Cai W., Fu C., Lin Z., Deng X., Ceram. Int., 37 (2011), 3643.

[27] Choi Y.K., Hoshina T., TAKeda H., Teranishi T., Tsurumi T., Appl. Phys. Lett., 97 (2010), 212907.

[28] Wu L., Chure M.Ch. Wu K.K., Chang W.Ch., Yuang M.J., LiU W.K., Wu M.J., Ceram. Int., 35 (2009), 957.

[29] Brennan C., Ferroelectrics, 150 (1993), 199.

[30] Shin W.Y., Shin W.H., Aksay I.A., Phys. Rev. B., 50 (1994), 15575.

[31] Hsi C.S., Chen Y.C., Jantunen H., Wu M.J., Lin T.C., J. Eur. Ceram. Soc., 28 (2008), 2581.

[32] Wang W., CaO L., LiU W., Su G., Zhang W., Ceram. Int., 39 (2013) 7127.

[33] Yu M., Hu J., LiU J., Li S., J. Magn. Magn. Mater., 326 (2013), 31.

[34] Ko Y.N., Choi S.H., Kang Y.C., J. Eur. Ceram. Soc., 33 (2013), 1335.

[35] Xin C.R., Zhang J., LiU Y., Zhang Q.L., YANG H., Cheng D., Mater. Res. Bull., 48 (2013), 2220.

[36] Wieczorek-Ciurowa K., Dulian P., Bąk W., Kajtoch C., Przem. Chem., 90 (2011), 1400. (in Polish).

[37] Wieczorek-Ciurowa K., Dulian P., Nosal A., DomagaŁa J., J. Therm. Anal. Calorim., 101 (2010), 471.

[38] Dulian P., Bąk W., Wieczorek-Ciurowa K., KAJTOCH C., Mater. Sci.-Poland, 31(2) (2013), 462.

Received 2013-08-27 Accepted 2014-03-06 